\title{
Hybrid e-Learning in Industrial Revolution 4.0 for Indonesia Higher Education
}

\author{
Husain Syam ${ }^{\#}$, Muhammad Basri ${ }^{\# *}$, Amirullah Abduh ${ }^{\#}$, Andi Anto Patak ${ }^{\#}$, Rosmaladewi $^{+}$ \\ ${ }^{\#}$ Universitas Negeri Makassar, Makassar, 90221, Indonesia \\ E-mail: "muhammadbasri@unm.ac.id \\ ${ }^{+}$Politeknik Pertanian Negeri Pangkep, Indonesia
}

\begin{abstract}
Hybrid e-learning brings traditional learning together digital learning to accommodate the current development technology era as Industrial Revolution 4.0. The study aims to explore the perceptions, strategies, and challenges of lecturers in using hybrid e-learning in their teaching. This case study employs both quantitative and qualitative methods. The quantitative data were used on-line questionnaire, and the qualitative data are gained via interviews. The quantitative data were analyzed using SPSS descriptive statistics, and the qualitative data were analyzed through interactive thematic data analysis. The findings reveal that there are several categories of the usefulness of hybrid, the institutional support, the impact of hybrid e-learning on subject mastery, and the percentage use of hybrid e-learning. Also, lecturers encounter mostly practical challenges in using hybrid e-learning. The study implies that lecturers may adopt the strategies of applying hybrid e-learning used by lecturers for a similar setting in different contexts. The study recommends that the more familiar the lecturers with the updated technology, the better the use of technology in their teaching. More importantly, the use of hybrid e-learning should be in the form of formal policy of the university so that it will be used ubiquity in many academic activities and settings. Higher education institutions should be able to change learning models that are by the needs of the Industrial Revolution 4.0 era
\end{abstract}

Keywords — hybrid; e-learning; higher education; industrial revolution 4.0.

\section{INTRODUCTION}

There is a debate on the application of hybrid e-learning in developing countries. Hybrid e-learning combines traditional learning with digital learning [1], [2]. It helps transform the traditional ways of learning and accommodate the new part of the current development technology, which is called "Industrial Revolution 4.0" [3]-[5]. The accommodation of the Industrial Revolution 4.0 can encourage the motivation and spirit of lecturers to learn new things or new technological application for learning so that they can transform their learning to become update technologies. Dues to these reasons, the hybrid e-learning is essential to further research.

To prepare lecturers in dealing with the industrial revolution 4.0 and the development of learning in the $21 \mathrm{st}$ century [6], educational institutions should create innovative and flexible learning, which is accessible anytime and anywhere. The digital world is experiencing rapid development. With the start of the development of internet use, the emergence of electronic learning methods, or better known as hybrid e-learning, can bridge lecturers and students in the teaching and learning process. Lecturers are required to improve their ability to provide education for students, especially using e-learning methods. The transition of traditional approaches to e-learning-based media has difficulty in building a culture or rather than making instruments, so this also needs attention.

It is expected that e-learning can increase learning flexibility as students become more open and efficient [7]. Universities must initiate an e-learning based curriculum and academic teaching processes [8]. This is done from the use of modules [9] to the learning method using video conference facilities. Educational institutions are expected to be able to prepare a new learning model that adapts to the industrial revolution 4.0 era, which is currently developing. Although we believe there are still advantages of face-toface learning modes, these modes of learning will slowly shift to distance learning, which is undoubtedly carried out without reducing the quality of education [10]. The learning process will be adapted to the development of the era of the Industrial Revolution 4.0. The transformation of education from traditional to digital e-learning is done to facilitate the learning process that can penetrate national and time boundaries. 
Not only has that, but the use of e-learning also suppressed cost efficiency without reducing the quality of learning. So that later, the learning model will be run using flexible technology such as smartphones. Teaching materials can convert to flexible technology, smartphones [11]. Lecturers can make teaching materials in the form of PowerPoint so that students can read teaching materials via mobile phones, no need for laptops anymore. Later students can access teaching materials including videos, wherever they are whether on the beach, in the mall or other places. With this learning method, it is expected that what is offered can answer the challenges in the industrial era 4.0 in the world of education. The challenge to adjust it should not be a burden for educators, especially lecturers, to deliver learning to students should be able to bring innovation for lecturers to make more exciting and innovative materials [12].

The development of technology and information has influenced various aspects of life. In the field of education, the impact that arises is the existence of online learning activities. For example, students could access the enormous number of reading resources in their desktop and start writing immediately without visiting the traditional library [13]-[16]. Along with this, online-based learning is increasingly being applied in the learning process in higher education [17]. Universities must prepare themselves in using the concept of e-learning to improve and develop knowledge, insights on academic principles, methodology and teaching skills to improve the quality of the learning process and student learning outcomes [1], [12], [18], [19].

Low lecture's attendance rate requires an immediate right response. In response to these problems, in the era of industrial revolution 4.0, this requires the state to expand public access to education services in general and higher education in particular through the implementation of elearning that is applied to all campuses in Indonesia. Efforts are needed to provide knowledge, skills, and motivation to the lecturers to be able to implement learning electronically. Lecturers could integrate Student Centre Learning (SCL) with e-learning [20], and be able to apply contextual learning [21]. This e-learning will also be ready to be filled by lecturers from abroad to provide lectures.

However, there are some of the challenges that are still faced in online education in Indonesia. First, there is still a lack of stakeholder and management support in implementing e-learning [22]. This obstacle is usually found in institutions that have not been fully aware of the potential and opportunities for using e-learning in supporting the learning process in the current era. Second, infrastructure readiness in some regions is still far from the expectations to support optimal e-learning [23]; it is a fundamental factor in the implementation of e-learning. Third, the lack of utilization of facilities in Learning Management Systems (LMS) for the learning process [23]. Even though some institutions already have an e-learning system, their usage is still limited to the repository of learning materials, and there are still not many usages of the interaction features between lecturers and students. The use of online learning systems in Indonesia has begun to have to move from using the LMS and other ICT-based tools, to the process of in-depth study to investigate the extent of the impact of using online learning systems on student learning achievement and teaching effectiveness conducted by lecturers. Online education research is very urgent in Indonesia due to a massive number of universities, the enormous number of students, a considerable number of lecturers and opportunities for online education.

The research of hybrid e-learning has been conducted in several countries. For example, a study on hybrid e-learning in Uganda [24], Bulgaria [25], Singapore [17], Pakistan [26], UK [27], and developed countries [19]. It can be seen that not many studies of hybrid learning conducted in East Asia, particularly within the Indonesian contexts.

In Indonesia, many of the studies conducted in higher education context have not focused on hybrid e-learning such as identity and language learning [28] and the cognitive elements of educational policy [29]. As a consequence, none of the research has investigated comprehensively on the perceptions, the strategies, and challenges of hybrid elearning in Indonesian higher education. This article addresses the limited publication of hybrid e-learning application within the university setting. This study has both theoretical and practical benefits. Theoretically, this study adds the debate on the implementation of hybrid e-learning globally, and this study benefits lecturers and educators for university contexts. This study can become an important reference for researchers, students, and educational stakeholders. Therefore it is essential to understand the basic concept of hybrid e-learning.

Several authors have defined the concept of hybrid elearning; it is a mixture of the face-to-face classroom and online learning [2]. Hybrid e-learning comprises partially online or virtual learning where students do not meet faceto-face in the same physical environment and partly face-toface interchange ideas where students face to face in the same classroom setting [27]. Hybrid e-learning encompasses the flexibility type of learning where on one hand teachers utilize the local resources that could be used for learning, and on the other, teachers employ a sophisticated online technology that is available and affordable for them [30]. For this definition, hybrid learning relates to the combination of modern means of technology and traditional forms of learning where students sit and listen to a lecture within similar physical setting and environment. The hybrid elearning has basic characteristics that differ from another form of the learning model.

Several studies have discussed the key characteristics of hybrid learning. Hybrid e-learning is characterized by $50 \%$ online and $50 \%$ face to face [27]. It also uses a computer without internet connection where the delivery of the lesson can use television and computer with internet connection where the delivery of lesson can be done via the online tutorial or upload a video on YouTube channel [26]. Hybrid e-learning is collaborative learning between teachers and students that is adaptive, purposive, and measurable [18]. Also, hybrid e-learning should be available the updated technology that can enhance the process of learning and interaction among teachers, students, and technicians.

Previous studies on hybrid e-learning have been conducted in several parts of the world. A study conducted in a Singaporean university indicates that the use of online learning or hybrid e-learning requires participants to be fully 
well-trained with the current technology. This is due to the hybrid learning employing sophisticated and contemporary technological development. For example, the learning is conducted via webinar; this requires participants to be familiar with the learning tools, conference tools, and discussion tools available in the webinar e-learning system. As a consequence, the hardware and the software installed on the computer system for participants should be compatible with the system and software used by teachers from a distance. Otherwise, technical problems may occur during the process of learning [17]. Therefore, a well-trained and well-prepared technician during the learning process can be an alternative action for the success of hybrid e-learning.

The other study conducted in the Bulgarian context shows that the use of ICT either for online learning or hybrid elearning. It brings several benefits for teachers, such as it changes the way the teacher deliver their teaching materials. ICT alters the condition of the teaching environment and provides new perspectives for students. Also, it offers further chances to try new thing and could be a learnercentered approach when they master the use of technology in their learning. More importantly, the teacher can deliver their teaching based on the students' preferences and choices and provide rapid response to students' issues during the process of teaching. Besides, the use of ICT for hybrid or face to face learning brings cost-efficient for teaching [25]. For these benefits, hybrid e-learning through the use of ICT based model could be applied where any supporting facilities and environment are fully equipped and supported by a policy on using ICT for hybrid learning.

To investigate further of the hybrid learning in an Indonesian higher education, researchers establish the following research questions.

- What are the lecturers "perceptions of using hybrid learning for their lecture?

- What are the challenges of using effective and meaningful hybrid learning?

\section{MATERIALS AND METHODS}

\section{A. Materials}

The materials in this study are research instruments in the form of an online survey and interview protocol. The questions of the online survey sent to the participants of the study via Google form. A survey is a data collection that aims to gather information about individuals and popularly used by almost all disciplines, mainly in social sciences [31]. The other instrument used in this study is the interview protocol contains the interview guidelines. The conditions needed for conducting interviews were specified in the interview guidelines that state the requirements or characteristics of the research subject/interviewee; it benefits as eyewitness memory [32]. The interview part of the study is in the form of open-ended questions, which are related to the questions on the online survey session.

\section{B. Method}

The data gathered from the online survey were analyzed descriptively; whereas, the interview data were analyzed thematically. Thematic analysis is the method of identifying themes that are patterned in a phenomenon [33]-[35]. This means the theme of the interview forms were placed according to the questions that appeared in the online survey.

\section{RESUlTS AND DISCUSSION}

\section{A. Participants' Sex Background}

The sex background of the participants is more than half is male participants. This indicates that male teachers use more hybrid learning than female lecturers.

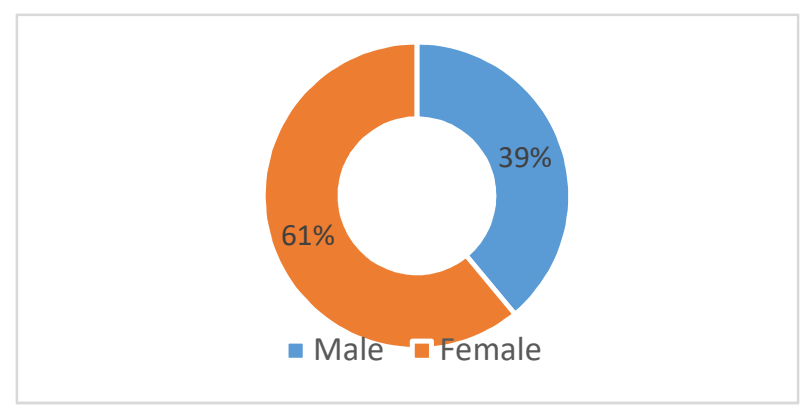

Fig. 1 Sex background of participants

The portraits of the sex background of the participants show that the hybrid e-learning is used more by female lecturers in their teaching and learning process. Among 42 participants, $26.8 \%$ of them graduates from master's degree, and $73.3 \%$ is doctoral degree.

\section{B. Length of Teaching Profession}

Length of the teaching profession among participants is varied. The nearly half $(46.3 \%)$ of the participants have spent more between five and ten teaching, $34.1 \%$ of them have spent teaching between 10 and 15 years, and $17.1 \%$ of them have involved in the profession more than 15 years. Interestingly, only $1 \%$ have spent time between one and five years for teaching.

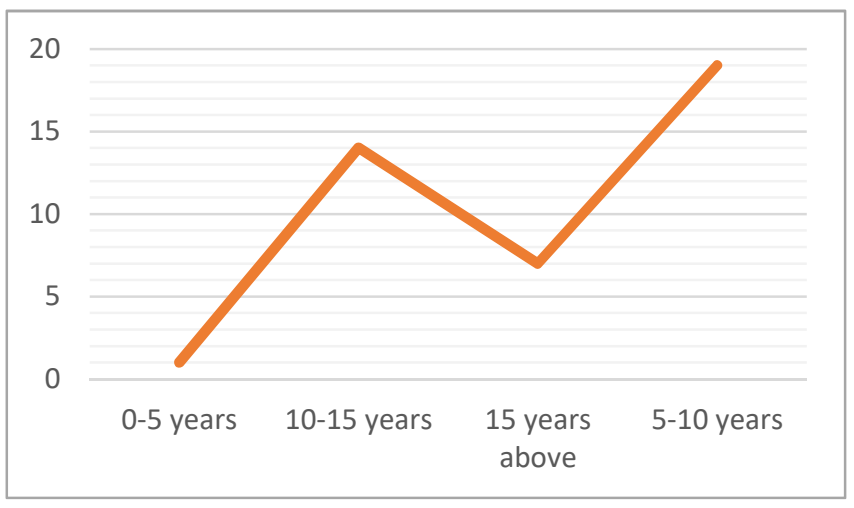

Fig. 2 Length of the teaching profession

This study also found that the majority of the participants have background knowledge of hybrid learning. Figure 2 indicates that most participants in this study are wellexperienced lecturers who have actively involved in their lecturers 'profession. These experienced lecturers have background knowledge on ICT and hybrid learning. 


\section{The Hybrid Learning Training}

Figure 3 below shows that all lecturers' have been trained with the ICT or the use of technology in their teaching and learning. However, not all of them have familiar with hybrid learning.

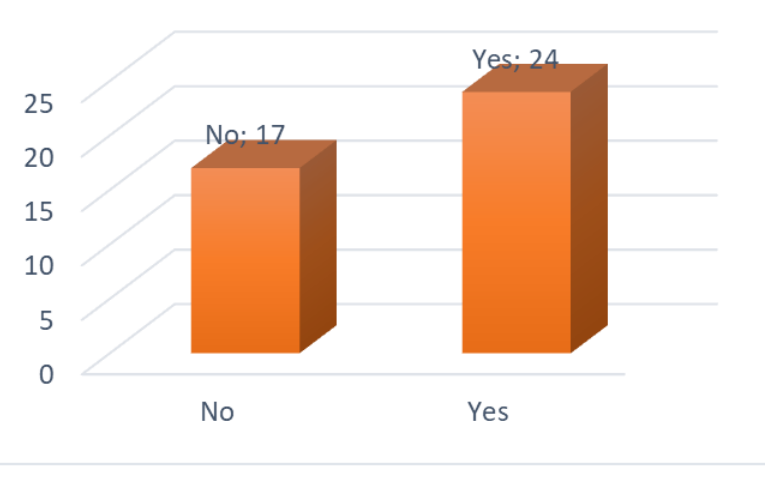

Fig. 3 Familiarity of hybrid e-learning

It can be seen from Figure 3 above that $58.5 \%$ of the participants have strong familiarity with hybrid e-learning. The data means that they can design, implement and do many of teaching tasks through hybrid e-learning. More importantly, they can manage and administer all related hybrid activities relating to their teaching. Despite the fact that $41.5 \%$ of the participants have less familiarity with the hybrid, they tend to have the basic understanding and foundation of the use of the Internet and ICT related activities. This data means that lecturers in this category have used either partially ICT application or limited ICT application.

About the familiarity of hybrid e-learning, participants provide applications of hybrid e-learning such as Edmodo, WebCT, Macromedia flash, Web-based learning, E-learning, Mendeley application, Claroline, Online journal system, Blended learning, Spada (long-distance online learning), Moodle, Google Classroom, Eschool, and Hot potatoes. The Edmodo application, for example, has several types of elements that are accessible and applicable for teachers to use for free. The Edmodo elements are based on the types of role in the e-learning: teachers' role, students' role, administrative role, and parent roles. Each role has a significant implication for access, use, and manage the application.

\section{The Usefulness of Hybrid E-Learning}

Based on participants' responses, there are three categories of the usefulness of hybrid e-learning: very useful, useful, and limited useful, (see Figure 4). Lecturers interestingly and extensively use the hybrid e-learning in their teaching and learning. Figure 4 indicates the benefit of the hybrid of e-learning for lecturers. Lecturers find that hybrid e-learning helps them to organize their teaching materials regularly, help them store learning resources online, and help them to mark students' work easily. The hybrid e-learning can assist lecturers in creating small groups online, assist the lecturers in listening to students' presentation if they are absent from face to face meetings. In addition, lecturers can mark and score students' tasks practically and locate students' work safely so that they can retrieve the data once they need them in the future.

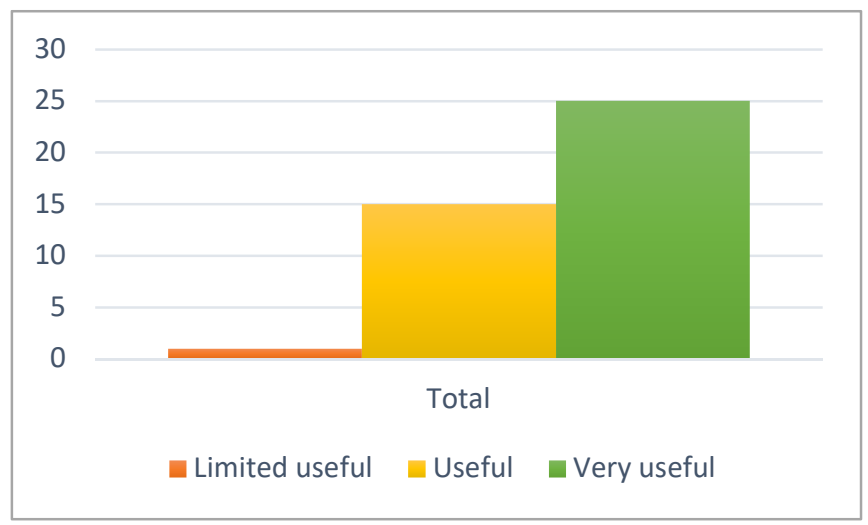

Fig. 4 The usefulness of hybrid e-learning

\section{E. The Institutional Attitude toward the Use of Hybrid e- Learning}

The responses about institutional attitude vary from the total participants in this study. The institutional support can be seen from Figure 5 below.

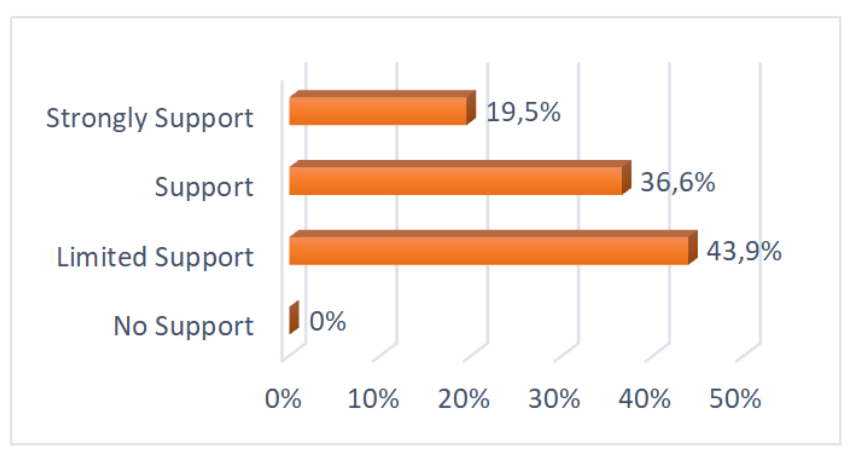

Fig. 5 Institutional attitude on the use of hybrid e-learning

The institutional supports can be seen from participants' responses. The support varies from the budget, wifi equipment, and the implementation of teaching and learning via hybrid learning. In terms of budget, participants indicate that "the institution support the budget" (Participant 7). About wifi equipment, participants' comments:

- Participant 1: Wifi is available in the campus area, example, digital classroom management by using google classroom and moodle

- Participant 11: The university provides Wi-fi

- Participant 5: Prepared an internet connection

- Participant 9: Provide training for Spada/hybrid elearning

- Participant 10: The institution provides students with internet facility for teaching \& learning process

In addition, several participants have indicated that the institution has supported the use of hybrid learning for teaching and learning implementation. They comment:

- Participant 1: Make the learning process is more effective

- Participant 3: We must submit an assignment through web

- Participant 4: To increase students motivation in learning 
- Participant 6: The system in teaching and learning process starts to use e-learning, an example in giving a task and material for the students
Lecturers in this study have used hybrid e-learning in their teaching and learning process in a different category. The detail of the category can be seen from Figure 6 below.

\section{F. The Percentage of Using Hybrid e-Learning}

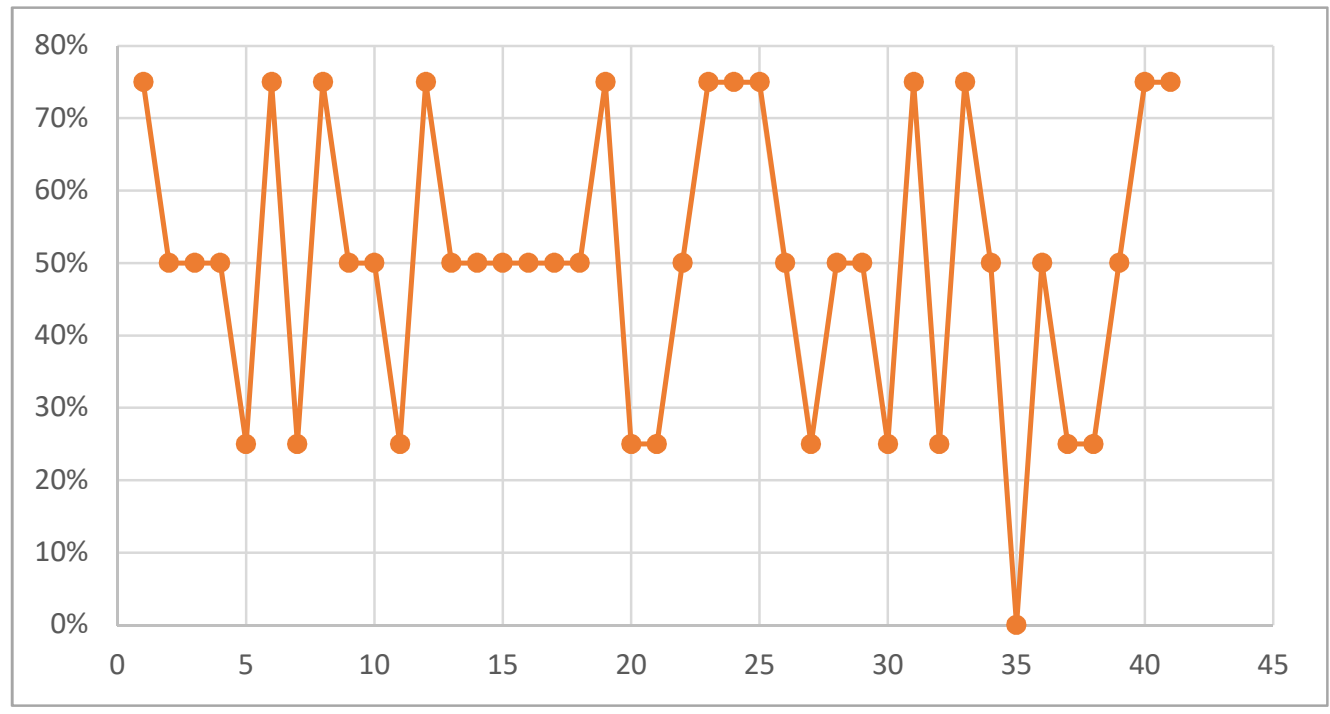

Fig. 6 Percentage of using hybrid in their teaching

Figure 6 indicates the percentage of lecturers using hybrid in their teaching and learning. It can be said that thirty percent of the participants had used the majority of their teaching using the hybrid model. Fifty percent of the participants have utilized hybrid e-learning model for half of their teaching and learning. Twenty percent of the participants have used a hybrid system for several sections of their teaching, such as submitting an assignment, doing task online, and searching for update references and module. The data in Figure 6 means that participants in this study have implemented hybrid learning in many parts of their teaching and learning. Therefore, they have a strong understanding of hybrid, strong awareness, and commitment to applying the hybrid system in their teaching and learning. The data in Table 1 indicates that participants use specifically in their teaching preparation, teaching practice, and completing an assignment, task, and evaluation. The teaching preparation may include searching required reading books and complimentary reading materials, searching for material comparisons from other universities, preparing syllabus and types of assignment, and preparing models and strategies for teaching.

TABLE I

THE DETAILED USE OF HYBRID E-LEARNING

\begin{tabular}{|l|l|}
\hline $22 \%$ of participants & $\begin{array}{l}\text { Teaching preparation, teaching practice, } \\
\text { assignment, task and evaluation }\end{array}$ \\
\hline $22 \%$ of the participants & Teaching preparation and teaching practice \\
\hline $22 \%$ of the participants & Assignment, task, and evaluation \\
\hline $12.2 \%$ of the participants & Teaching practice \\
\hline $9.8 \%$ of the participants & Teaching preparation \\
\hline $7.3 \%$ of the participants & $\begin{array}{l}\text { Teaching preparation, assignment, task, and } \\
\text { evaluation }\end{array}$ \\
\hline $4.7 \%$ of the participants & $\begin{array}{l}\text { Teaching practice, assignment, task, and } \\
\text { evaluation }\end{array}$ \\
\hline
\end{tabular}

The teaching practice can include the delivery of the lessons, students' presentation via distance e-learning model, upload and download the teaching materials provided in the hybrid e-learning system. The assignment section can include submitting an assignment, asking the types of assignment, understanding, and reading assignment instruction. Finally, the evaluation activities include marking students' assignment, providing feedback, and comments on students' progress.

\section{G. The Impact of Hybrid E-Learning on Subject Mastery}

It can be seen from Figure 7 below that there is a strong tendency where students' mastery of the subject matters increases as a result of using hybrid learning. Figure 7 illustrates that none of the lecturers' participants believe that hybrid e-learning provides a negative impact on students learning. However, they are all confident that the availability of hybrid e-learning supports high mastery of subjects. This data means that hybrid e-learning enhances and students learning especially the mastery of the contents. All lecturers in this study believe that facilities provided in the hybrid elearning can facilitate the understanding of the subjects.

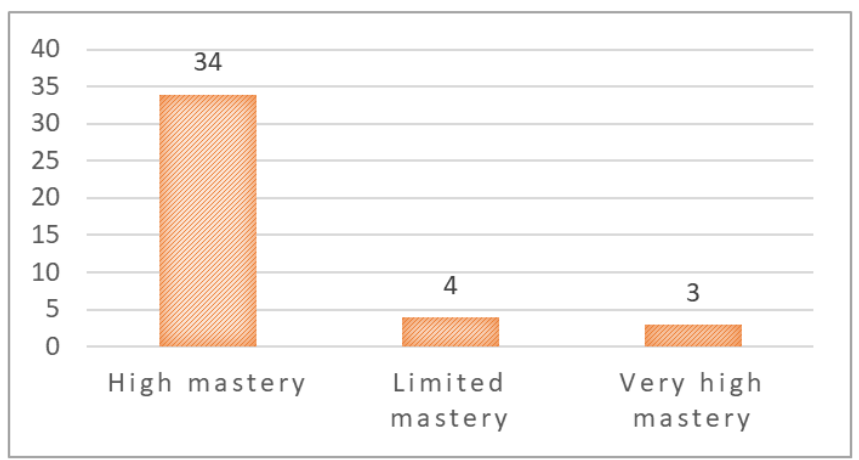

Fig.7 The impact of hybrid e-learning on subject mastery 


\section{H. The Challenges of Applying Hybrid e-Learning}

Even though lecturers' participants have stated the positive impact on mastery of subjects, they still encounter some challenges in the implementation of hybrid e-learning.
Figure 8 below describes the detailed explanation of the challenges they face when lecturers implement hybrid elearning for their teaching and learning.

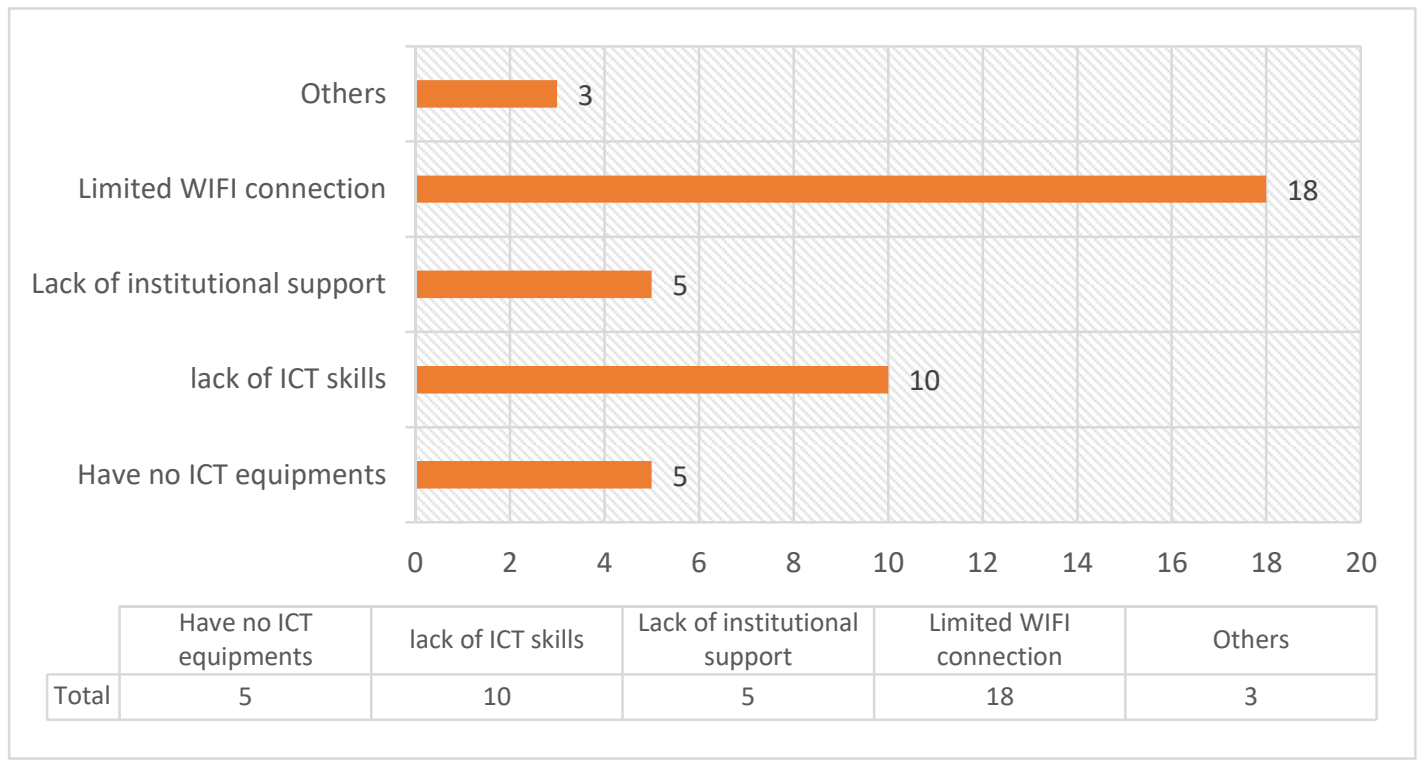

Fig. 8 Challenges of applying hybrid e-learning

There are five categories of lecturers' participants' responses. Majority of the participants $(43 \%)$ indicate that limited Wifi connection is the major challenges in applying hybrid e-learning in higher education. The second challenge is that lack of ICT skills and training because many of the lecturers do not pay attention to the mastery of ICT skill needed for hybrid e-learning. The third challenge is that it requires strong support from the institutions. The fourth is some of the students and educators have limited ICT equipment that is eligible for hybrid e-learning. Finally, the other category is that limited time for hybrid e-learning and limited frequency of using hybrid e-learning for students and lecturers.

\section{CONCLUSION}

A country certainly has to make changes in various fields. Especially nowadays, when Indonesia is dealing with the era of industrial revolution 4., where competition is increasingly tight. One of the changes can be formed by improving human resources. Facing the 4.0 industrial revolution is certainly not an easy thing. Several things need to be prepared, for example, by changing the learning methods in the world of education that exist today. The state needs to change three things in terms of education. The most fundamental is to change the nature and mindset of a student today.

Furthermore, the university must be able to hone and develop a student's talents. Also, higher education institutions should be able to change learning models from the traditional approach to hybrid e-learning that is by the needs of the Industrial Revolution 4.0 era. The government needs to provide facilities that suit the needs of the student and support the lecturers to be more familiar with hybrid elearning.
The more familiar lecturers to the application of hybrid elearning, the easier the way they apply the hybrid e-learning for their teaching and learning. Also, the less the challenges they encounter during the application of hybrid learning, the more effective the application of hybrid for their teaching and learning. The more application of the hybrid e-learning applied by lecturers, the better the result of the students' study result, particularly concerning subject mastery. However, the familiarity of lecturers on hybrid e-learning is not an assurance to meet the Industrial Revolution 4.0 demand without the existence of some aspects.

The institution should guarantee that all the equipment required are available. The institution also should provide institutional support and ensure the availability of Wifi connection. Thus, it is expected that the familiarity of lecturers on hybrid e-learning could meet the four principles in the Industrial Revolution 4.0. Firstly, interoperability, which is the ability of machines, devices, sensors, and humans to connect and communicate with each other through the Internet of Things (IoT) media [36]. Secondly, transparency of information, i.e., the ability of information systems to create copies of the physical world virtually by enriching digital factory models with sensor data. Thirdly, technical assistance, specifically the ability of the assistance system to help humans collect data and create visualizations to make wise decisions and the ability of a cyber-physical system to help humans perform various difficult, unpleasant, or unsafe tasks for humans. Lastly, an autonomous decision which includes the ability of the cyber-physical system to make decisions and perform tasks as independently as possible.

It is suggested that more studies can be conducted in many areas that are not the focus of this current study. The further study can be explored in the field of students' perceptions of applying hybrid e-learning, policymakers' perceptions on the application of hybrid e-learning, and the 
practitioners' perceptions of implementing hybrid e-learning in Industrial Revolution 4.0. The upcoming study could be directed to explore the competence of lecturers in using hybrid e-learning to meet the four principles in Industrial Revolution 4.0, which involves the interoperability, information transparency, technical assistance, and autonomous decision. In addition, future research is important to be conducted in a more holistic perspective, multiple sets, and various levels of educational institutions. This current research can become pivotal references for future studies of lecturers and educational stakeholders about the implementation of hybrid e-learning in Industrial Revolution 4.0.

\section{REFERENCES}

[1] M. Martyn, "The hybrid online model: Good practice," Educ. Q., vol. 26, no. 1, pp. 18-23, 2003.

[2] N. A. Buzzetto-more, "Hybrid Learning Defined," J. Inf. Technol. Educ., vol. 5, no. 1, pp. 153-156, 2006.

[3] N. Tvenge and K. Martinsen, "Integration of digital learning in industry 4.0," Procedia Manuf., vol. 23, pp. 261-266, 2018.

[4] M. Baygin, H. Yetis, M. Karakose, and E. Akin, "An effect analysis of industry 4.0 to higher education," in 2016 15th international conference on information technology-based higher education and training (ITHET), 2016, pp. 1-4.

[5] B. Xing and T. Marwala, "Implications of the fourth industrial age for higher education," Think., no. 73, 2017.

[6] A. A. Hussin, "Education 4.0 made simple: Ideas for teaching," Int. J. Educ. Lit. Stud., vol. 6, no. 3, pp. 92-98, 2018.

[7] H. M. S. Ahmed, "Hybrid E-Learning acceptance model: Learner perceptions," Decis. Sci. J. Innov. Educ., vol. 8, no. 2, pp. 313-346, 2010.

[8] A. Benešová and J. Tupa, "Requirements for education and qualification of people in Industry 4.0," Procedia Manuf., vol. 11, pp. 2195-2202, 2017.

[9] C. Prinz, F. Morlock, S. Freith, N. Kreggenfeld, D. Kreimeier, and B. Kuhlenkötter, "Learning factory modules for smart factories in iIndustrie 4.0," Procedia CiRp, vol. 54, pp. 113-118, 2016.

[10] K. Schuster, L. Plumanns, K. Groß, R. Vossen, A. Richert, and S. Jeschke, "Preparing for industry 4.0-Testing collaborative virtual learning environments with students and professional trainers.," Int. J. Adv. Corp. Learn., vol. 8, no. 4, 2015.

[11] S. Jaschke, "Mobile learning applications for technical vocational and engineering education: The use of competence snippets in laboratory courses and industry 4.0," in 2014 International Conference on Interactive Collaborative Learning (ICL), 2014, pp. 605-608.

[12] A. Klašnja-Milićević, B. Vesin, M. Ivanović, and Z. Budimac, "ELearning personalization based on hybrid recommendation strategy and learning style identification," Comput. Educ., vol. 56, no. 3, pp. 885-899, 2011

[13] A. Hudriati, A. A. Patak, and M. Basri, "Assessing Indonesian University Students, Preferences on Mendeley Reference Manager for Scientific Writing," Int. J. Adv. Sci. Eng. Inf. Technol., vol. 8, no. 5, pp. 2211-2218, 2018.
[14] A. A. Patak, H. A. Naim, and R. Hidayat, "Taking Mendeley as Multimedia-based Application in Academic Writing," Int. J. Adv. Sci. Eng. Inf. Technol., vol. 6, no. 4, p. 557, Aug. 2016.

[15] M. Basri and A. A. Patak, "Exploring Indonesian students' perception on Mendeley Reference Management Software in academic writing," in 2015 2nd International Conference on Information Technology, Computer, and Electrical Engineering (ICITACEE), 2015, pp. 8-13.

[16] A. A. Patak and E. Akib, Mendeley: citation \& PDF reference manager plus jejaring sosial. Arus Timur, 2012.

[17] C. Guan, D. Ding, and K. W. Ho, "E-Learning in Higher Education for Adult Learners in Singapore," Int. J. Inf. Educ. Technol., vol. 5, no. $5,2015$.

[18] A. Tsai and C. Yun, "A Hybrid E-learning Model Incorporating Some of the Principal Learning Theories," Soc. Behav. Pers., vol. 39, no. 229 , pp. 145-152, 2011.

[19] I. Zitter and A. Hoeve, "Hybrid Learning Environments: Merging Learning and Work Processes to Facilitate Knowleedge Integration andf Transitions," OECD Educ. Work. Pap., vol. 81, no. 01, 2012.

[20] B. P. Woolf, Building intelligent interactive tutors: Student-centered strategies for revolutionizing e-learning. Morgan Kaufmann, 2010.

[21] E. B. Johnson, Contextual teaching and learning: What it is and why it's here to stay. Corwin Press, 2002.

[22] H. Firman and B. Tola, "The future of schooling in Indonesia," J. Int. Coop. Educ., vol. 11, no. 1, pp. 71-84, 2008.

[23] R. D. Kuntoro and S. Al-Hawamdeh, "E-learning in higher educational institutions in Indonesia," J. Inf. Knowl. Manag., vol. 2, no. 04 , pp. 361-374, 2003.

[24] P. O. Lating, Hybrid E-learning for Rural Secondary Schools in Uganda. Sweden: Bleking Institute of Technology, 2006.

[25] V. Terzieva, E. Paunova, and P. Kademova-katzarova, "Implementation of ICT Based Teaching in Bulgarian Schools."

[26] S. K. Toor, "Hybrid Model for e-Learning at Virtual University of Pakistan," Elev. J. e-Learning, vol. 3, no. 1, pp. 1-10, 2005.

[27] F. G. Hamza-lup and S. White, "Design and Assessment for Hybrid Courses : Insights and Overviews,” vol. 7, no. 3, pp. 122-131, 2015.

[28] A. Abduh and R. Rosmaladewi, "Language policy, identity, and bilingual education in Indonesia: a historical overview," XLinguae, vol. 12, no. 219-227, 2019.

[29] R. Ramly and A. Abduh, "Exploring Cognitive Concepts in the National Assessment of the Indonesian Language," New Educ. Rev., vol. 53, no. 3, pp. 142-152, 2018.

[30] L. C. Medina, "Blended learning: Deficits and prospects in higher education," Aust. J. Educ. Technol., vol. 34, no. 1, pp. 42-56, 2018.

[31] A. Aldridge and K. Levine, Surveying the Social World. Buckingham - Philadelphia: Open University Press, 2001.

[32] R. P. Fisher and N. Schreiber, "Interview protocols to improve eyewitness memory," Handb. Eyewitness Psychol. Vol. I Mem. Events, 2017.

[33] V. Braun, V. Clarke, N. Hayfield, and G. Terry, "Thematic analysis," Handb. Res. Methods Heal. Soc. Sci., pp. 843-860, 2019.

[34] G. Guest, K. M. MacQueen, and E. E. Namey, Applied thematic analysis. Sage, 2011.

[35] R. E. Boyatzis, Transforming qualitative information: Thematic analysis and code development. Sage, 1998.

[36] M. T. Okano, "IOT and industry 4.0: the industrial new revolution," in International Conference on Management and Information Systems September, 2017, vol. 25, p. 26. 